\title{
Bosniak Classification and other Variables in the Prediction of Renal Cystic Masses
}

\author{
Bugra Keseroglu1, Berat Cem Ozgur1, Sedat Tastemur², Lokman Irkilata3, Ömer Gökhan Doluoglu \\ and Cem Nedim Yücetürk1
}

\begin{abstract}
Objective: To evaluate the variables of cystic renal lesions to predict the renal tumors.

Study Design: An observational study.

Place and Duration of Study: Urology Department, Ankara Yüksek Ihtisas, Samsun Research and Training Hospitals, Turkey, from January 2013 to June 2017.

Methodology: Records of patients with renal cystic lesions were retrospectively evaluated. Preoperative CT results in terms of diameter number and enhancement; and clinical variables such as gender body mass index [(weight $(\mathrm{kg}) /$ height $\left.^{2}(\mathrm{~m})\right]$ and smoking status were recorded. Student's t-test and ANOVA were used for determing significance, which was set at $p<0.05$.

Results: Due to pathology results, all group I patients were benign, $7.9 \%(3 / 38)$ of group II, $31.8 \%(7 / 22)$ of group II-F, $55.3 \%(21 / 38)$ of group III, $69 \%$ (40/58) group IV patients were found to be malignant. For clinical factors, obesity and smoking, while for radiological parameters, about $59.3 \pm 11.7 \mathrm{HU}$ enhancement were found to be predictor significant of malignancy (all $\mathrm{p}<0.05$ ). No significant difference was observed between cystic lesion diameter number or laterality (right/left) and malignancy.

Conclusion: Renal cysts have a high malignancy possibility in the patients with history of smoking in the past or actively, high BMI, and preoperative CT with about $59.3 \pm 11.7 \mathrm{HU}$ post-contrast enhancement.
\end{abstract}

Key Words: Kidney diseases, Cystic, Computed tomography.

\section{INTRODUCTION}

Due to advances in medical technology, access to crosssectional abdominal imaging techniques has increased recently. As a result, the incidence of both cystic and solid renal neoplasm detection has increased while the first-detected tumor diameter has decreased. ${ }^{1}$ Computed tomography (CT) is frequently used in clinical evaluation and categorising of cystic renal masses. Criteria defined in the categorisation of renal cysts with CT was first described by Bosniak in 1986 and this classification was evoluated in 1993 (Table I).2,3

Although the pathology results for solid renal masses are intensively present in the literature, studies on cystic renal lesions are rather limited. For many, this classification has limited ability to determine malignancy and some lesions undergo unnecessary surgical interventions. ${ }^{4}$ Bosniak classification with postoperative pathology of renal cysts is based on visual enhancement only.

1 Department of Urology, Ankara Research and Training Hospital, Ankara, Turkey

2 Department of Urology, Ankara Yuksek Ihtisas Research and Training Hospital, Ankara, Turkey

3 Depatment of Urology, Samsun Research and Training Hospital, Samsun, Turkey

Correspondence: Dr. Berat Cem Ozgur, Department of Urology, Ankara Research and Training Hospital, Ankara, Turkey

E-mail: bcemozgur@hotmail.com

Received: July 07, 2018; Accepted: November 12, 2018
The aim of this study was to determine the Basniak classification features on CT scan, and some general clinical features, as predictors of malignancy in renal cystic masses.

\section{METHODOLOGY}

The records of 785 patients with renal cystic lesions operated at three tertiary institutions between January 2013 and June 2017 were retrospectively evaluated. Clinical data were obtained from hospitals' medical data. The patients who were operated with a solid mass diagnosis and those who underwent biopsy before the operation were excluded. Those with a discrepancy between the readers were also excluded. The final study group included 191 patients with 191 lesions. None of the patients had a known hereditary syndrome associated with renal tumors. All of the patients were evaluated with preoperative CT and treated surgically. These operations include laparoscopic cyst excision, open partial nephrectomy, laparoscopic partial nephrectomy and open radical nephrectomy. Post-contrast CT images were obtained after 30 seconds of bolus injection of iv. $2 \%$ barium sulfate. The dose was $2 \mathrm{ml} / \mathrm{kg}$ body weight at a rate of $3 \mathrm{ml}$ per second. All scanning and image reconstruction were done at $2.5 \mathrm{~mm}$ increments. The preoperative CT results of the patients were reassessed by two urologists after assessment of a radiologist. All HU measurements were made by single radiologist blinded to pathology reports. Also some clinical 
variables as body mass index [weight $(\mathrm{Kg}) /$ height $\left.^{2}(\mathrm{~m})\right]$ and smoking status were retrospectively recorded. Patients selected from answers to the question "Are you a smoker?" to describe their smoking status; never smoked, former smokers (at least half-pack daily for several years but not currently), moderate smokers (less than half a pack daily), heavy smokers (more than a pack daily) were also noted.

Statistical analyses were conducted using SPSS ${ }^{\circledR}, 22.0$ (NY, USA). Continuous variables are presented as mean \pm standard deviation, while categorical variables are given as percentages. Student t-test and ANOVA test were used to compare means for continuous variable factors and Chi-square test was used to analyse categorical variables. The statistical significance level was evaluated to be $p<0.05$.

\section{RESULTS}

The mean age of the patients was $57.0 \pm 6.7$ years. Ninety-seven $(50.8 \%)$ patients were males and 94 $(49.2 \%)$ were females. Of the 191 lesions, 35 were classified as Bosniak Type I (18.3\%), 38 as Bosniak type II (19.9\%), 22 as Bosniak type II-F (11.5\%), 38 (19.9\%) as Bosniak type III, and 58 as Bosniak type IV (30.3\%). The pathology results of all type I patients were benign; whereas, $7.9 \%(3 / 38)$ of type II patients, $31.8 \%(7 / 22)$ of type II-F patients, $55.3 \%$ of type III patients, and $79.3 \%$ (40/58) of type IV lesions were malignant. All the malignant pathologies were renal cell carcinoma (RCC); subtypes being 54 (76\%) clear cell, 10 (14.8\%) papillary cell, and 7 (9.8\%) multilocular cystic renal cell carcinomas. Clinical characteristics of the patients and pathological findings of Bosniak classification are shown in Table II.

In the analyses of radiologic parameters, no significant differences were observed between cystic lesion diameter $(5.72 \pm 1.59 \mathrm{~cm}$ etc. $5.31 \pm 2.06 \mathrm{~cm}, \mathrm{p}=0.119)$, or laterality (right/left) and malignancy. But significant difference was detected in HU enhancement. Moreover, there were significant differences in risk factors in multivariate analysis associated with RCCs patients with complicated renal cysts (e.g., smoking status, obesity). Table III summarises a comparison of parameters between benign and malignant cysts with statiscal significance.

Table III: Comparison of parameters according to pathology results.

\begin{tabular}{l|c|c|c}
\hline & Benign (n:120) & Malignant (n:71) & $\mathrm{p}$ \\
\hline Enhancement (HU) & $31.9 \pm 10.0$ & $59.3 \pm 11.7$ & $<0.05$ \\
Diameter (mm) & $57.2 \pm 15.9$ & $53.1 \pm 20.6$ & 0.119 \\
BMI>30 (kg/m $\left.{ }^{2}\right)(\%)$ & $21(17.5)$ & $32(45)$ & $<0.05$ \\
Smoking; former and current (\%) & $18(15)$ & $48(67.6)$ & $<0.05$ \\
Heavy smoking (\%) & $8(8.3)$ & $33(46.4)$ & $<0.05$ \\
\hline
\end{tabular}

\section{DISCUSSION}

Bosniak classification has been widely accepted by urologists and radiologists due to its clear boundaries that is easy to implement difficult clinical problems. Malignancy has been reported in very large proportions in complex cysts; it is reported that nearly $5 \%$ of RCCs are cystic. ${ }^{1}$ Unfortunately, when the patient is diagnosed for the first time, this distinction can usually not be clearly made. Several studies have demonstrated various different malignancy rates in different Bosniak catogories, which are in agreement with the present results. $4-6$ The malignancy rates of type II lesions were between $4-13 \%$ in previous studies, compared to $7.9 \%$ in this study. This comparison was $31.8 \%$ vs. $10-38 \%$ for type II-F, $55.3 \%$ vs. $38-84 \%$ for type III, and $69 \%$ vs. $61-82 \%$ for type IV. ${ }^{7}$

The most important points in diagnosis are benign versus malignant differentiation and surgical or nonsurgical treatment option distinction. Thickened irregular cyst wall, thick irregular septa, and enhancing soft tissue component on CT have been accepted as strong malignancy indicators. 8-10 In this study, it was found that post-contrast enhancement was a very important factor that helped to predict the pathology of the lesion. But wall and septum irregularity was not fully evaluated. according to some authors. The use of thinner slices for CT scans would be helpful in distinguishing between

Table I: Bosniak classification of renal cystic lesions.

\begin{tabular}{|c|c|c|}
\hline Category & Criteria & Malignancy rate \\
\hline Type I & Simple cyst with hairline thin wall without any calsifications, septas. & $1-5 \%$ \\
\hline Type II & $\begin{array}{l}\text { Contains few hairline thin septas. The diameter is less than } 3 \mathrm{~cm} \text {. Enhancing soft tissue does not exist. In the wall or septa a } \\
\text { short segment of thickened calcification might be seen. }\end{array}$ & $10-15 \%$ \\
\hline Type IIF & Contains multiple hairline septas. The diameter is more than $3 \mathrm{~cm}$. Enhancing soft tissue does not exist. & $15-30 \%$ \\
\hline Type III & $\begin{array}{l}\text { Contains thickened irregular or smooth walls or septa. Measurable enhancement is present. Infected cysts, nephroma, and } \\
\text { cystic neoplasms. }\end{array}$ & $50-60 \%$ \\
\hline Type IV & These lesions have clearly enhancing soft tissue components, the other features are similar to Type III. & $80-90 \%$ \\
\hline
\end{tabular}

Table II: Baseline characteristics of analysed patients.

\begin{tabular}{|c|c|c|c|c|c|}
\hline Bosniak type & I (n:35) & II (n:38) & IIF (n:22) & III (n:38) & IV (n:58) \\
\hline Age & $57.9 \pm 7.1$ & $56.8 \pm 6.8$ & $56.4 \pm 6.3$ & $56.4 \pm 9.1$ & $57.1 \pm 4.7$ \\
\hline Sex, male:female & 13:22 & $18: 20$ & $2: 20$ & $24: 14$ & $40: 18$ \\
\hline Diameter (mm) & $6.0 \pm 1.8$ & $5.7 \pm 1.8$ & $5.4 \pm 1.3$ & $5.6 \pm 1.5$ & $5.1 \pm 2.0$ \\
\hline Pathology, malignant:benign & $0: 35$ & $3: 35$ & $7: 15$ & $23: 15$ & $48: 10$ \\
\hline Laterality, right:left & $13: 22$ & $17: 21$ & $14: 8$ & $24: 14$ & $26: 28$ \\
\hline
\end{tabular}


benign and malignant lesions, avoiding unnecessary surgical intervention or choosing a less invasive surgical method. ${ }^{1}$ Variation exists across radiologists and a standardised template should have to be defined in order to decrease these inconsistencies. In the current study, increments of $2.5 \mathrm{~mm}$ were chosen and that interval might be a standard level in evaluating cystic renal lesions. The calculations found that decreasing the increment interval significantly increases the radiation exposed.11,12 The current interval had a high accuracy of detecting the malignancies without a dissonance between three experts.

It is also of utmost importance that the Bosniak classification is implemented with a close collaboration between the urologist and the radiologist. ${ }^{13} \mathrm{Kim}$ et al. performed a study with multidetector $\mathrm{CT}$; and two readers evaluated the $C T$ results seperately. ${ }^{14}$ The most important debate was that there was a disagreement between readers' CT results of type II, type II-F and type III. But the authors did not find a major disagreement among the three readers (one radiologist and two urologists; while all three were blinded to each other's results. Only ten of $201(4.9 \%)$ patients were excluded because of the contradictions in the evaluation.

On the other hand, some easily available clinical parameters like smoking status, BMI were also evaluated. In a multi-center retrospective study by Smith et al., type II, II-F and III patients were placed under active surveillance, and surgery were evaluated. 3 Gender, body mass index, Charlson comorbidity index, smoking, and race were not significantly different between the groups. ${ }^{3}$ In the study conducted by Oh et al., smoking history, hypertension, and obesity were found to be statistically significant predictors of malignant renal cysts in comparison with benign malignant group among all patients. ${ }^{15}$ These results were similar to the present findings, where smoking and high BMI were also found to be the predictors of malignancy. Heavy smoking (more than a pack per day) was a stronger predictor. Careful evaluation must be completed before making a decison to this type of lesions; and surgical exploration should be a choice when the urologist is in doubt.

This study has some limitations including its retrospective design, and that the number of patients was very small. In the current study, one radiologist and three different urologists assessed the CT scans; and if any doubt was found, the patient was excluded from the study. That is one of the reasons of the limited number of the patients. Third, HU measurements were made by only a single reader only and thickness of solid components and invasive mass effect etc. were not studied. This study is based on a homogenous group, which consisted of Turkish patients only. Finally, passive smoking status was not determined. Nevertheless, it was identified that smoking is potentially risk factor of malignancy in renal cystic lesions. Still, the current findings have the potential to provide useful context for urologist. Although larger studies may be required in the future to clarify the data, the patients with high $\mathrm{HU}$ enhancement smoking history and high BMI, one must consider a high risk of malignancy in renal cystic lesions. The treatment protocol should proceed in this direction.

\section{CONCLUSION}

Significant positive malignancy was detected and found at $59+17 \mathrm{HU}$ enhancement besides smoke exposure and high BMI.

\section{REFERENCES}

1. El-Galley R. Surgical management of renal tumours. Radiol Clin North Am 2003; 41:1053-65.

2. Song C, Min GE, Song K, Kim JK, Hong B, Kim CS, et al. Differential diagnosis of complex cystic renal mass using multiphase computerized tomography. J Urol 2009; 181:2446-50.

3. Smith $A D$, Allen $B C$, Sanyal $R$, Carson JD, Zhang $\mathrm{H}$, Williams JH, et al. Outcomes and complications related to the management of Bosniak cystic renal lesions. AJR Am J Roentgenol 2015; 204:550-6.

4. Lam CJ, Kapoor A. The true malignancy risk of Bosniak III cystic renal lesions: Active surveillance or surgical resection? Can Urol Assoc J 2018; 12:E276-80.

5. Remzi M, Marberger M. Renal tumor biopsies for evaluation of small renal tumors: Why, in whom, and how? Eur Urol 2009; 55:359-67.

6. Israel GM, Bosniak MA. Renal imaging for diagnosis and taging of renal cell carcinoma. Urol Clin North Am 2003; 30:499-514.

7. Bielskiene N, Augustinavicius V, Valanciene D, Tamošiunas AE, Jankevicius F. Bosniak category III renal lesions: Likelihood of malignancy based on computed tomography findings. Cent European J Urol 2018; 71:58-63.

8. Whelan T. Guidelines on the management of renal cyst disease. Can Urol Assoc J 2010; 4:98-9.

9. Prasad SR, Dalrymple NC, Surabhi VR. Cross-sectional imaging evaluation of renal masses. Radiol Clin North $\mathrm{Am}$ 2008; 46:95-111

10. Weber TM. Sonography of benign renal cystic disease. Radiol Clin North Am 2006; 44:777-86.

11. Weir VJ, Zhang J. Radiation dose measurements in a 256-slice computed tomography scanner. J Med Phys 2018; 43: 85-92.

12. Piergallini L, Scola E, Tuscano B, Brambilla R, Campoleoni M, Raimondi G, et al. Flat-panel CT versus 128-slice CT in temporal bone imaging: Assessment of image quality and radiation dose. Eur J Radiol 2018; 106:106-13.

13. Edenberg J, Gløersen K, Osman HA, Dimmen M, Berg GV. The role of contrast-enhanced ultrasound in the classification of CT-indeterminate renal lesions. Scand J Urol 2016; 50:445-51.

14. Kim MH, Yi R, Cho KS, Choi HJ. Three-phase, contrastenhanced, multidetector CT in the evaluation of complicated renal cysts: Comparison of the postcontrast phase combination. Acta Radiol 2014; 55:372-7.

15. Oh TH, Seo IY. The role of Bosniak classification in malignant tumor diagnosis: A single institution experience. Investig Clin Urol 2016; 57:100-5.

$$
\text { .......... }
$$

